\title{
The impact of sleep in fibromyalgia, an exploratory study
}

\begin{abstract}
Fibromyalgia has been referred to as one of the most common rheumatological pathologies in the world's population, coming in fourth place in Spain and Bangaldesh, second in the USA, Brasil and Mexico (Assumpção, 2006). Regarding the recovery cases of people who sought help at Clínica da Mente, prior to this study, with complaints regarding emotional issues and who had Fibromyalgia, this study aims to investigate to which extent the perception of quality of sleep affects the perception of pain in patients with fibromyalgia. The results point to a significant correlation between quality of sleep and perception of pain $(\rho=0,994$ para $p \leq 0,01)$. It was also demonstrated that emotional states such as depression, anxiety and stress disturb the perception of quality of sleep. As such, emotional states condition sleep, which in turn conditions the perception of pain in patients with fibromyalgia.
\end{abstract}

Keywords: fibromyalgia, sleep, depression, anxiety, HBM psychotherapeutic intervention
Volume 9 Issue 5 - 2018

\author{
Cécile Domingues, Carla Oliveira, Isabel \\ Gomes, Joana Oliveira, Marta Calado \\ Clinica de Mente, Portugal
}

Correspondence: Cécile Domingues, Clinica de Mente, Portugal, Email ceciledomingues@clinicadamente.com

Received: April 12, 2018| Published: September 26, 2018

\section{Introduction}

Fibromyalgia is characterized as a chronic diffuse pain disease and sensitivity to pain in certain areas of the body as muscles tendons and ligaments. Patients diagnosed with fibromyalgia have as main complaints non-restful sleep, tiredness and permanent diffuse pain. ${ }^{1}$ The clinical and scientific recognition of fibromyalgia as a pathological entity was achieved recently, being as it is, a pathology that sparks a great deal of interest in the midst of the medical community. ${ }^{2}$ The informative note (Circular Informativa, in the original language) $\mathrm{n}^{\circ} 45$ / DGDG (Portugal, 2005) defines fibromyalgia as being a "Rheumatic disease of unknown cause and functional nature, that originates generalized pains in the soft tissues, such as muscles, ligaments or tendons, but does not affect joints or bones" (p.1). Fibromyalgia is caused by a complex combination of physical and emotional factors ${ }^{3}$ that cause a change in the communication between body, brain and central nervous system. ${ }^{4}$ As such, the emotional and psychological state is permanently influenced and influences the neurophysiological processing of pain and the behavioural attitudes of patients, reducing their quality of life as well as their productivity. ${ }^{5,6}$ According to com Giesecke, et al., ${ }^{7}$ the prevalence of emotional disorders in patients with fibromyalgia is larger than with patients with other rheumatological diseases. The most common emotional disorders in fibromyalgic patients are anxiety, somatization, dysthymia, panic attacks, post-traumatic stress and depression. ${ }^{8-10}$ This syndrome affects men and women without social or ethnical distinction. It is known that the prevalence rate is higher in women between the ages of 20 and 50 (Myos) and that fibromyalgia affects about $2 \%$ of the adult population. ${ }^{11}$ The symptoms of fibromyalgia appear with varying intensity and frequency from person to person. The severity of these symptoms is, nonetheless, often debilitating and incapacitating. ${ }^{12}$ "Although the exact cause of fibromyalgia is not known, there are several changes associated to it that could be in its genesis. (...) Pain, fatigue mood swings and changes in sleep patterns are the main symptoms". ${ }^{13}$

\section{Fibromyalgia and sleep}

Sleep is a basic human necessity. It the rest period in which the transitory interruption of perceptive-sensorial and voluntary motor activity occurs. ${ }^{14}$ It is a valuable physiological necessity, indispensable to a healthy balance, that has the biological functions of restoration of the organism and maintenance of energy, allowing physical and emotional equilibrium. ${ }^{15} \mathrm{~A}$ routine of badly slept nights and unadjusted sleep causes tension, irritability, tiredness, fatigue, muscle pains, headaches, light depression and anxiety symptoms, decreased intellectual performance, daytime somnolence and reduced reaction time (that increase driving and work accidents), reduced concentration and productivity. ${ }^{16,17}$ Disturbed quality of sleep was reported and recognized in patients with fibromyalgia. In accordance to Marques (2008), Gui and collaborators (2010) and Spitzer \& Bradman, ${ }^{18}$ sleep disturbances are referred as one of the main causes of the intense fatigue usually present in this illness. Thus, the existence of a non-restorative sleep presents itself as a relevant factor amongst the symptoms of fibromyalgia, which shows the importance of studying primary sleep disorders in the diagnosis of these patients. ${ }^{19}$ Nevertheless, it is not yet clear if this sleep disorder is the origin or the consequence of chronic pain. ${ }^{19-22}$

\section{Fibromyalgia and emotional well-being}

There are several studies on the impact of fibromyalgia on the quality of life (Buchardt et al., 1992; Buchardt, et al., 1993) and on functionality and work capacity trabalho. ${ }^{23-25}$ Gaston-Johansson et al. (1999, quoted by Quartilho, ${ }^{26}$ in a study with 31 women with fibromyalgia, found that these patients presented low self-esteem and felt insecure. Countless studies ${ }^{27,28}$ refer that living with a disease that is imperceptible to others is exhausting for people with fibromyalgia, thus significantly affecting their quality of life. Alongside what happens in other chronic pathologies, depression is usual among patients with fibromyalgia, occurring in 30 to $50 \%$ of the cases. ${ }^{29}$ Their manifestations can be mistaken with the symptoms of fibromyalgia, although it hasn't been demonstrated as a subcategory of depressive disorder. In relation to anxiety, studies have revealed that approximately $1 / 3$ of patients with fibromyalgia suffer from anxiety disorder. ${ }^{29}$ According to Pimenta, ${ }^{30}$ the depressive and anxious manifestation is usually related to painful situations. Although it is difficult to determine the cause-effect relation, there is evidence that 
emotional disorders such as depression and anxiety tend to increase the pain, with higher occurrence in patients with pain and chronic pain. Research as that of Sardá, ${ }^{31}$ Cruz, ${ }^{32}$ Caldas, ${ }^{33}$ Sardá $^{34}$ and Frutuoso $^{35}$ indicate that the occurrence of depressive, anxious and somatic symptoms can occur with the instauration, maintenance and intensification of the intensity of pain.

\section{Methodology and presentation of results}

The objective of this study is to understand the impact that HBM ${ }^{\circledR}$ Therapy has on fibromyalgia, by studying the quality of sleep and emotional disorders such as depression and anxiety. This is a quantitative experimental study with pre and post-test and one-year follow-up.

\section{Investigation hypothesis}

Hypothesis 1: Quality of sleep influences the perception of pain.

Hypothesis 2: Anxiety significantly influences the quality of sleep, so the higher the levels of anxiety the lower the perception of quality of sleep will be.

Hypothesis 3: Anxiety significantly influences the perception of pain and so the higher the levels of anxiety greater will be the pain felt.

\section{Instruments}

The objectives of the study, as well as the characteristics of the sample group, were considered to choose the data collection instruments.

\section{Escala visual analógica (EVA) - (visual analogic scale)}

The EVA is a scale that measures the intensity of pain and has been considered sensitive, simple, reproducible and universal. ${ }^{36}$ The scale is composed by a horizontal (or vertical) line $10 \mathrm{~cm}$ long, that has, on one end "Without Pain" and on the other "Maximum Pain". There is an equivalence between the intensity of Pain and the point on the straight line, thus obtaining a numeric score that will be noted on the registration sheet. ${ }^{37}$

\section{Pittsburgh quality of sleep index}

The Pittsburgh Quality of Sleep Index (PSQI) evaluates the quality of sleep in an individual. It is made up of nineteen self-response questions. The authors of the scale present a cutting point of .5. Indexes higher or similar to 5 suggest individuals with low quality of sleep. ${ }^{38}$

\section{Anxiety, dpression and stress scale (EADS-2I)}

The Anxiety, Dpression and Stress Scale (EADS-21) (Lovibond e Lovibond, 1955) was adapted to the Portuguese population by PaisRibeiro, Honrado e Leal (2004) and is made up by 21 questions and each variable is measured by 7 items, presented on a Likert scale. Each item consists of a phrase that relates to negative emotional symptoms related to anxiety, depression and stress. Higher scores correspond to more negative emotional states.

\section{Social demographic questionnaire}

The questionnaire was based on parameters that situate the participants in the study, gender, age, marital state, employment situation, profession and education, the existence or not of social and family support, date of beginning of symptoms of pain and diagnostic of fibromyalgia, amongst others.

\section{Impact of fibromyalgia questionnaire (FIQ-P)}

This instrument, developed by Burckhart, Clark e Bennett (1991) was translated and validated to the Portuguese population by Rosado et al., ${ }^{39}$ to measure the state of health and functional capacity of patients with fibromyalgia and to evaluate their clinical evolution, as well as their therapeutic results. The values of the FIQ-P vary between 0 and 100, with 100 indicating the maximum impact of fibromyalgia. Rosado et al., ${ }^{39}$ considered the existence of 3 groups for the global value: without impact or un severe impact up to 50 , moderate impact or moderately severe impact from 50 to 70 and severe impact or very severe impact above 70 .

The internal consistency presented a value of $\alpha=0.814$.

\section{Sample selection criteria and characterization of the target population}

The participants in the study were recruited according to the following criteria:
1. Age (above 18years of age)
2. Medical fibromyalgia diagnostic
3. Residence in the Porto district

This was a non-probabilistic convenience sample, since these were easily accessible subjects. ${ }^{40}$ The sample was comprised of 10 participants $(\mathrm{N}=10), 100 \%$ female, the average age was 48,40 years old with an age gap from 42 to 53 . As far as marital state, $50 \%$ of the participants were married. As far as education, the $12^{\text {th }}$ grade, high school, is the most common level of education, $40 \%$ of the sample group. As for the frequency of pain, $60 \%$ of the participants refer suffering from the disease for over 20 years, experiencing pain daily $(90 \%)$ regularly over the years $(60 \%)$. As for the sleep pattern, $100 \%$ of the group slept less than 7 hours a night and mentions waking up frequently during the night.

\section{Procedure}

Initially there was an evaluation and diagnosis session, by the psychotherapists, to identify the emotional and psychological disorders of each subject. The diagnosis was followed by the filling out of the psychometric questionnaires, before the HBM psychotherapeutic intervention. Afterwards there were weekly psychotherapeutic sessions for 4 weeks, in which the therapists, specialized in the HBM method, used the Athenese ${ }^{\circledR}$ and Morfese ${ }^{\circledR}$ techniques. According to Brás, ${ }^{41}$ the HBM Psychotherapeutic Intervention Model is based on the study of the Map of Human Behaviour, that describes the conscious and unconscious mental processes, allowing to explain the way of thought and behaviour of human beings. There are two techniques used in HBM Therapy: Athenese ${ }^{\circledR}$ and Morfese ${ }^{\circledR}$. Their function is to work the individual's emotional system so that he/she can be freed of emotions such as angst, fear, sadness, anxiety, among others, leading to the change of their depressive or anxious state. ${ }^{41}$ Athenese ${ }^{\circledR}$ is made up of psychotherapeutic exercises in which conscious imagination is used as a means to re-signify, thus helping the individual to articulate new strategies of thought and understanding of reality. ${ }^{41}$ Morfese ${ }^{\circledR}$ is a technique of emotional liberation through the induction of a guided dream, by the therapist, in which the subject achieves an intermediate state between vigil and sleep. Unconscious thought is used to dissociate from past disturbing experiences, allowing the individual to associate to positive experiences. ${ }^{41-46}$ After the 4 weeks, the individual participants filled out the questionnaires again. Then again one month 
later and then one year after the intervention.

\section{Statistical data methods}

The data obtained was analysed using the Statistical Package for Social Sciences ${ }^{\circledR}$ (SPSS) software and XLSTAT. Initially the techniques used were descriptive statistics (frequencies, percentages, means, averages and standard-deviation) and statistical inference analysis of the hypothesis using the independence test of Chi-Squared (X2), for a probability of error type I $(\alpha)$ of 0,05 . With the purpose of testing the normality of the sample, the normality test KolmogorovSmirnov was used. The levels of significance obtained allow assuming that the sample follows a normal distribution, using the Pearson correlation test, to test associations between variables.

\section{Results}

\section{Objective I}

It was concluded that the variable pain relates significantly with the Pittsburgh Sleep Quality Index $(\rho=0,994$ para $p \leq 0,01)$. Thus, inferring the existence of a relation between quality of sleep and perception of intensity of pain. The higher the score on the Pittsburgh Sleep Quality Index (bad quality), the higher the score on the Visual Analogic Scale (EVA) (in which a high score relates to strong pain). The quality of sleep influences the perception of pain.

\section{Objective 2}

The results obtained allow to infer that the perception of sleep quality positively relates to anxiety $(\rho=0,990$ para $p \leq 0,01)$, with depression $(\rho=0,983$ para $p \leq 0,01)$ and stress $(\rho=0,945$ para $p \leq 0,05)$. The data indicates the influence cause-effect of the variables anxiety, depression and stress in the perception of sleep quality in the participants. The perception of quality of sleep depends on the states of anxiety, depression and/or stress. Since there is a positive correlation between these variables, the higher the values in the emotional state variables, the higher the score in the Pittsburgh Sleep Quality Index, thus showing a compromised quality of sleep.

\section{Objective 3}

The Pearson correlations obtained between the Visual Analogic Scale of pain and the sub scales Anxiety, Depression and Stress of the Anxiety, Depression and Stress scale allow us to infer the existence of positive significative relations between the Visual Analogic Scale and Anxiety $(\rho=0,999$ para $p \leq 0,05)$, between the Visual Analogic Scale and Depression $(\rho=0,995$ para $p \leq 0,05)$, between the Visual Analogic Scale and Stress $(\rho=0,969$ para $p \leq 0,01)$. As such we may infer that the higher the levels of Anxiety, Depression and Stress, the higher the intensity of perceived pain will be.

\section{Conclusion}

This study had as its main objective to asses to what extent the perception of quality of sleep affects the perception of pain in patients with fibromyalgia. With regards to the results we may infer the existence of very strong correlations between quality of sleep, perception of pain, perception of quality of sleep with some emotional states such as Anxiety, Depression and Stress.

Regarding Hypothesis 1, the results point to a significative correlation between quality of sleep and perception of pain $(\rho=0,994$ para $p \leq 0,01$ ). In this sense, the lower the quality of sleep, the higher the level of perceived pain. This result emphasises the importance of healthy sleep.

Regarding Hypothesis 2, the analysed data shows significant relations between the perception of quality of sleep and different emotional states such as: Depression $(\rho=0,983$ for $p \leq 0,01)$, Anxiety ( $\rho=0,990$ for $p \leq 0,01)$ and Stress $(\rho=0,945$ for $p \leq 0,05)$. Specifically, the greater the emotional disorders, the lower the perceived sleep quality. According to Brás, ${ }^{41}$ sleep represents a mechanism that switches off our consciousness from our surroundings and that leaves the individual vulnerable to environmental and circumstantial dangers. This author explains that quality of sleep intrinsically depends on the notion of perceived danger. When there is danger, animals, including humans become alert afraid that danger may mean pain or discomfort. "These states of vigilance disturb our capacity to switch off from the present and fall asleep" (Brás, 2010, p.20). ${ }^{41}$ Regarding Hypothesis 3 , significant correlations were found between the perception of pain and the referred emotional disorders. As such, the greater the levels of anxiety $(\rho=0,999$ for $p \leq 0,01)$, depression $(\rho=0,995$ for $p \leq 0,01)$ and 7 or stress $(\rho=0,969$ for $p \leq 0,05)$, the greater the perceived intensity of pain will be. According to the results presented, we can infer a causality relation between the emotional states and the perception of quality of sleep. Anxiety, Depression and Stress represent variables that can compromise the quality of sleep. ${ }^{41}$ In the same sense, the existence of a strong correlation between quality of sleep and perception of pain in fibromyalgia patients was demonstrated. The changes in sleep and pain were a direct consequence of the change in emotional state. And so, we can infer that fibromyalgia presents a psychological etiology to triggering physical symptoms.

\section{Limitations of the investigation}

This study intends to give its contribution to the understanding of fibromyalgia, and more specifically, its consequences in the perception of quality of sleep and the perception of intensity of pain. Yet, being an exploratory study, the presented results cannot be generalized to the entirety of the population with fibromyalgia due to the size of the sample being too small. Nonetheless, with such a high correlation between the hypothesis, this study opens a clear path for future studies with more representative sample groups with fibromyalgia patients that could prove, more consistently, these same results.

\section{Acknowledgements}

None.

\section{Conflict of interest}

The auhtor declares no conflict of interest.

\section{References}

1. Sampaio M. O julgamento médico: regimes de envolvimento dos atores em situação: o caso da Fibromialgia. Dissertação de Doutoramento. Faculdade de Ciências Médicas da Universidade Nova de Lisboa; 2010.

2. Giamberardino M. Update on fibromyalgia syndrome. Pain Clinical Updates. 2008;16(4):16.

3. McIlwain H, Bruce D. The Fibromyalgia Handbook. Henry Holt and Company LLC: New York; 2007.

4. American college of rheumatology. Arthritis \& Rheumatism. 2003;48(10):2916-2922.

5. Heymann R. O papel do reumatologista frente à Fibromialgia e à dor 
crónica músculo- esquelética. Revista Brasileira de Reumatologia. 2006;46(1):1-2.

6. Heymann R. New concepts in Fibromyalgia. Update-Medical Education Program in Orthopedics; 2012.

7. Giesecke T, Williams D, Harris R, et al. Subgrouping of fibromyalgia patients on the basis of pressure- pain thresholds and psychological factors. Arthritis and Rheumatism. 2003;48(10):2916-2922.

8. Katon W, Sullivan M, Walker E. Medical symptoms without identified pathology: relationship to psychiatric disorders, childhood and adult TRAUMA, and personality traits. Annals of Internal Medicine. 2001;134(9 Pt 2):917-925.

9. Cohen H. Prevalence of post- traumatic stress disorder in fibromyalgia patients: overlapping syndromes or post- traumatic fibromyalgia syndrome? Seminars in Arthritis and Rheumatism. 2002;32(1):38-50.

10. Epstein S. Psychiatric disorders in patients with fibromyalgia: a multicenter investigation. Psychosomatics. 1999;40(1):57-63.

11. Portugal. Fibromialgia - Circular informativa $n^{\circ} 45 / D G C G$. Ministério da Saúde. Direção Geral da Saúde Web Site; 2005.

12. Nampiaparampil D, Shmerling R. A review of fibromyalgia. Am J Manag Care. 2004;10(11 Pt 1):794-800.

13. Domingues M, Branco J. Viver com Fibromialgia: a visão da doente e do médico. Gradiva: Lisboa; 2008.

14. Buratto J. Sono e insônia. 2009

15. Rente P, Pimentel T. A patologia do sono. Lidel: Lisboa; 2004

16. Ferrão A. Higiene do sono; 2010

17. Rosales E. Martha Egoavil, Claudia La Cruz, et al. Somnolencia y calidad del sueño en estudiantes de medicina de una universidad peruana. Anales de la Facultad de Medicina. 2007;68(2):150-158.

18. Spitzer R, Broadman M. A retrospective review of the sleep characteristics in patients with chronic fatigue syndrome and fibromyalgia. Pain Practice. 2010;10(4):294-300.

19. Teixeira M, Yeng L, Kaziyama S. Fibromialgia e sono. In: Reimão R editor. Avanços em Medicina do Sono. São Paulo: Associação Paulista de Medicina; 2001

20. McCain G. Fibromyalgia and myofascial pain syndromes. In: PD Wal R, Melzack, editors. Textbook of pain. 3rd ed. New York: Churchill Livingstone; 1994.

21. Moldofsky H. Sleep and Pain. Sleep Medicine Reviews. 2001;5(5):387398.

22. Braz A. Uso da terapia não farmacológica, medicina alternativa e complementar na Fibromialgia. Revista Brasileira de Reumatologia. 2011;51(3):275-282.

23. Henriksson C. Impact of Fibromialgia on everyday life: A study of women in the USA and Sweden. Disability \& Rehabilitation. 1996;18(5):241-248.

24. Henriksson KG. Fibromyalgia From Syndrome to Disease. Overview of pathogenic mechanisms. Journal of rehabilitation Medicine. 2003;(41 Suppl):89-94.

25. Wolfe F, Clauw DJ, Fitzcharles MA, et al. The American College of Rheumatology: preliminary diagnostic criteria for fibromyalgia and measurement of symptom severity. Arthritis Care \& Research. 2010;62(5):600-610.

26. Quartilho M. Fibromialgia: Consenso e Controvérsia. Acta Reumatológica Portuguesa. 2004;29:111-129.

27. Söderberg S, Lundman B, Norberg A. Struggling for dignity: the meaning of women's experiences of living with fibromyalgia. Qual Health Res. 1999;9(5):575-587

28. Sturge-Jacobs M. The experience of living with fibromyalgia: Confronting an invisible disability. Res Theory Nurs Pract. 2002;16(1):19-31.

29. Provenza Jr, Pollack D, Martinez J. Fibromialgia. Revista Brasileira de Reumatologia. 2004;44(6):443-449.

30. Pimenta C. Fundamentos teóricos da dor e de sua avaliação. In Carvalho MMJD. editor. Dor: um estudo multidisciplinar, Summus: São Paulo; 1999. p. 31-46.

31. Sardá J. Avaliação Psicológica de estados emocionais associados às síndromes dolorosas. Dissertação de Mestrado em Psicologia. Florianópolis: Universidade Federal de Santa Catarina; 1999.

32. Cruz R. psicodiagnóstico de síndromes dolorosas crônicas relacionadas ao trabalho. Tese de Doutoramento em Engenharia de Produção e Sistemas. Florianópolis: Universidade Federal de Santa Catarina; 2001.

33. Caldas W. Avaliação Psicológica de síndromes dolorosas crónicas relacionadas ao trabalho. Projeto de pesquisa do programa PIBIC/ CNPq, Florianópolis: Universidade Federal de Santa Catarina; 2002.

34. Sardá J. Avaliação Psicológica em pacientes com dor crônica. In: RM Cruz, et al. editors. Avaliação e Medidas Psicológicas. Casa do Psicólogo: São Paulo; 2002.

35. Frutuoso J. Mensuração de Aspectos Psicológicos em Portadores de dor crônica relacionada ao Trabalho. Tese de Doutoramento em Engenharia de Produção e Sistemas. Florianópolis: Universidade Federal de Santa Catarina; 2006.

36. Azevedo A. Eficácia da acupunctura no tratamento dos sintomas na fibromialgia: projeto de investigação. Dissertação de Mestrado. Instituto de Ciências Biomédicas de Abel Salazar. Universidade do Porto; 2010.

37. Portugal. A dor como $5^{\circ}$ sinal vital: registo sistemático da intensidade da dor. Direção Geral da Saúde Web Site; 2003. p. 1-4.

38. Buela Casal G. Sanchez A. Transtornos del sueño. Editorial Síntesis: Madrid; 2002

39. Rosado M, João Pedro, José Pascoalinho, et al. Cultural adaptation and validation of Fibromyalgia impact questionnaire: English version. Acta Rheumatológica Portuguesa. 2006;31(2):157-165.

40. Gomez G, Flores J, Jimènez E. Methodology of qualitative research Aljibe editions: Málaga; 1996.

41. Brás P. Manual HBM. Unpublished document. London: Master HBM Research; 2010

42. APDF. Associação Portuguesa de Doentes com Fibromialgia (APDF)

43. Assumpção A. Prevalence of Fibromyalgia and evaluation of associated symptoms, functional capacity and quality of life in the population of the city of Embu, São Paulo [online]. Master's Dissertation, Faculty of Medicine - University of São Paulo; 2017.

44. Moldofsky H. Effects of sodium oxybate on sleep physiology and sleep/wake-related symptoms in patients with fibromyalgia syndrome: a double-blind, randomized, placebo-controlled study. J Rheumatol. 2010;37(10):2156-2166.

45. Pais Ribeiro J, Honrado A, Leal I. Contribution to the study of the Portuguese adaptation of the depression, anxiety and stress scales (EADS) of 21 items of Lovibond and Lovibond. Psychology, Health and Diseases. 2004;5(2):229-239.

46. Sampaio A. The role of optimism in the psychosocial adjustment of the fibromyalgic patient. Master's Dissertation - Faculty of Psychology and Educational Sciences of the University of Lisbon; 2008. 